\title{
Flora da Usina São José, Igarassu, Estado de Pernambuco, Brasil: Acanthaceae, Gesneriaceae e Loganiaceae
}

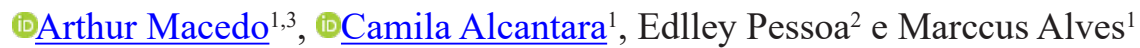

Recebido: 15 março 2019; aceito: 5 dezembro 2019

Como citar: Macedo, A., Alcantara, C. Pessoa, E. \& Alves, M. 2020. Flora da Usina São José, Igarassu, Estado de Pernambuco, Brasil: Acanthaceae, Gesneriaceae e Loganiaceae. Hoehnea 47: e252019. http://dx.doi.org/10.1590/2236$8906-25 / 2019$.

\begin{abstract}
Flora of the Usina São José, Igarassu, Pernambuco State, Brazil: Acanthaceae, Gesneriaceae and Loganiaceae). Acanthaceae, Gesneriaceae, and Loganiaceae are well-represented in Brazil and in the Neotropical region, although they have been poorly studied in northeastern Brazil, especially in the Atlantic Forest of Pernambuco State. Thus, aiming to contribute with the taxonomic knowledge about these taxa, this study had the objective of identifying and characterizing the species found in forest fragments of the Usina São José, in Igarassu, as a continuation of the monograph series for the area. Fieldwork was carried out between January 2017 and January 2018. Specimens from the herbaria CEPEC, HST, IPA, JPB, NY, PEUFR, RB, and UFP were also analyzed. Eleven species were found in the study area, five belonging to Acanthaceae, two to Gesneriaceae, and four to Loganiaceae. An identification key, descriptions, illustrations and comments on distribution and habitats are provided.
\end{abstract}

Keywords: Atlantic Forest, Brazil, floristic, lamiids

RESUMO - (Flora da Usina São José, Igarassu, Estado de Pernambuco: Acanthaceae, Gesneriaceae e Loganiaceae). Acanthaceae, Gesneriaceae e Loganiaceae são bem representadas na flora Neotropical e brasileira, no entanto são famílias pouco estudadas no Nordeste do país, em especial na Mata Atlântica do Estado de Pernambuco. Dessa forma, visando contribuir com o conhecimento taxonômico acerca desses táxons, este estudo teve como objetivo identificar e caracterizar morfologicamente as espécies ocorrentes nos fragmentos da Usina São José, localizada em Igarassu, dando continuidade à série de monografias para a área. Expedições de coletas foram realizadas na área entre janeiro de 2017 e janeiro de 2018. Os espécimes depositados nas coleções dos herbários CEPEC, HST, IPA, JPB, NY, PEUFR, RB e UFP também foram analisados. Para a área de estudo, foram encontradas onze espécies, cinco de Acanthaceae, duas de Gesneriaceae e quatro de Loganiaceae. São apresentados chave de identificação, descrições, ilustrações e comentários sobre distribuição geográfica e hábitats.

Palavras-chave: Brasil, florística, lamiídeas, Mata Atlântica

\section{Introdução}

Acanthaceae e Gesneriaceae integram a ordem Lamiales e Loganiaceae a Gentianales, todas agrupadas no subclado das Lamiídeas (APG IV 2016). Compartilham caracteres diagnósticos como folhas simples e opostas, simpetalia tardia ou transitória e estames epipétalos (Olmstead et al. 2000, Erbar \& Leins 1996, Christenhusz et al. 2017).

Acanthaceae é composta de cerca de 210 gêneros e 4.000 espécies (Wasshausen 2004, Christenhusz et al. 2017). São predominantemente ervas, arbustos ou subarbustos e, por vezes, trepadeiras com folhas opostas e sem estípulas. As inflorescências geralmente possuem brácteas vistosas e as flores são predominantemente zigomorfas e bilabiadas com dois ou quatro estames (Wasshausen 2004, Maas \& Westra 1993, Kameyama 2006). Possui distribuição majoritariamente tropical e subtropical, com centros de diversidade na região Neotropical, África, Sudeste Asiático e Índia, em especial no Brasil (Wasshausen 2004, Christenhusz et al. 2017), onde a família tem

1. Universidade Federal de Pernambuco, Departamento de Botânica, Cidade Universitária, Laboratório de Morfo-Taxonomia Vegetal, Avenida Professor Moraes Rego 1235, 50670-901 Recife, PE, Brasil

2. Universidade Federal de Mato Grosso, Departamento de Botânica e Ecologia, Boa Esperança, Avenida Fernando Corrêa da Costa 2367, Cuiabá, 78060-900 Cuiabá, MT, Brasil

3. Autor para correspondência: arthur.macedo.rocha@hotmail.com 
ampla distribuição. No país está representada por 39 gêneros e 445 espécies (BFG 2015, 2018).

Gesneriaceae é composta de cerca de 175 gêneros e 3.800 espécies (Denham 2004, Christenhusz et al. 2017). São de hábito predominantemente herbáceo ou subarbustivo, com folhas opostas, sem estípulas e com brácteas e bractéolas desenvolvidas e vistosas. As flores são zigomorfas com corola frequentemente gibosa, androceu com quatro ou cinco estames e estaminódios às vezes presentes (Denham 2004, Chautems 2000). Possui distribuição pantropical (Christenhusz et al. 2017), sendo representada no Brasil por 28 gêneros e cerca de 220 espécies, dos quais 14 gêneros e 34 espécies são encontrados no Nordeste (BFG 2015, 2018).

Loganiaceae é composta por 15 gêneros e cerca de 400 espécies (Gibbons et al. 2012, Christenhusz et al. 2017). São geralmente ervas, arbustos ou lianas com ou sem gavinhas e/ou espinhos (Strychnos) e raramente árvores (Antonia). As folhas são opostas com estípulas interpeciolares (caducas em Strychnos) e as flores são actinomorfas, geralmente hipocrateriformes ou infundibiliformes, com cinco estames (Struwe 2004, Zappi \& Setúbal 2016). Apesar da distribuição tropical, é mais diversa na região Neotropical, principalmente no Brasil (Ducke 1955, Struwe 2004), sendo reconhecidos cinco gêneros e 131 espécies, destas 67 são endêmicas, enquanto para o Nordeste são citados quatro gêneros e 48 espécies (BFG 2015, 2018).

Estudos taxonômicos envolvendo essas três famílias são pouco frequentes no Nordeste do Brasil, onde se pode citar os estudos de Harvey \& Wasshausen (1995), Kameyama (2009), Silva et al. (2010), Cortês \& Rapini (2013) para Acanthaceae, Chautems (1991), Woodgyer (1995) e Chautems et al. (2000) para Gesneriaceae e Chiappeta (1985), Zappi (1995), Nurit et al. (2005), Melo et al. (2009) e Brandão \& Rapini (2018) para Loganiaceae.

A escassez de estudos taxonômicos é uma das razões limitantes do conhecimento sobre a real diversidade e caracterização das mesmas para a região, em especial para a Mata Atlântica pernambucana. Assim, o objetivo desse trabalho foi inventariar e caracterizar morfologicamente as espécies de Acanthaceae, Gesneriaceae e Loganiaceae nos fragmentos florestais da Usina São José, Igarassu, Brasil, dando continuidade à série de monografias florísticas na região.

\section{Materiais e métodos}

A Usina São José (USJ) localiza-se no litoral norte de Pernambuco, a cerca de $40 \mathrm{~km}$ de Recife $\left(7^{\circ} 40^{\prime}\right.$ $\left.7^{\circ} 55^{\prime} \mathrm{S}, 34^{\circ} 54^{\prime}-35^{\circ} 05^{\prime} \mathrm{W}\right)$, cuja área total é de $280 \mathrm{~km}^{2}$, sendo composta por cerca de 100 fragmentos florestais inseridos em uma matriz de cana-de-açúcar (Trindade et al. 2008). A vegetação é classificada como Floresta Estacional Semidecidual de Terras Baixas, e possui significante diversidade de angiospermas com cerca de 830 espécies (Alves-Araújo et al. 2008, Melo et al . 2011, Alves et al. 2013).

Além das coletas realizadas pelo projeto Flora da Usina São José durante o período de 2009 a 2012, os fragmentos florestais denominados Chave, Macacos e Piedade, considerados os mais diversos quanto à flora (Alves et al. 2013), foram alvo de expedições adicionais de janeiro de 2017 a fevereiro de 2019. Os procedimentos de coleta e herborização de espécimes seguiram metodologia padrão (Peixoto \& Maia 2013).

A identificação dos táxons foi realizada com base em bibliografias especializadas, como Kameyama (2006), Profice (1997) e Sims (1825) para Acanthaceae, Chautems (1991), Feuillet \& Skog (2002) e Feuillet \& Steyermark (1999) para Gesneriaceae e Krukoff \& Monachino (1942), Krukoff \& Barneby (1969) e Chiappeta (1985) para Loganiaceae. Os protólogos das espécies foram analisados assim como as amostras-tipo quando disponíveis on-line. Também foram realizas consultas aos acervos dos herbários CEPEC, HST (Herbário Sérgio Tavares - UFRPE), IPA, JPB, NY*, PEUFR, RB* e UFP (Thiers et al., continuamente atualizado; "*" somente imagens). A terminologia morfológica segue Harris \& Harris (2001), complementada por Hickey (1973) para arquitetura foliar. A classificação proposta por Silva et al. (2008), adaptada (Gomes-Silva et al. 2018), foi aplicada para caracterizar os hábitats de Floresta Atlântica na área de estudo. O material foi incorporado no herbário UFP e duplicatas enviadas aos herbários $\mathrm{RB}$ e SP (Thiers et al., continuamente atualizado). Este trabalho segue o modelo apresentado nas monografias anteriores para a área de estudo (Buril \& Alves 2011, Pessoa \& Alves 2012, Maciel \& Alves 2014, CostaLima \& Alves 2015, Luna et al. 2016, Ferreira et al. 2017, Gomes-Silva et al. 2018, entre outras).

\section{Resultados e Discussão}

Foram encontradas onze espécies na área, sendo cinco Acanthaceae, duas Gesneriaceae e 
quatro Loganiaceae. Entre as Acanthaceae ocorrem Thunbergia alata Bojer ex Sims, uma espécie naturalizada no Brasil, Mendoncia blanchetiana Profice, Justicia sp, Lepidagathis alopecuroidea (Vahl) R.Br. ex Griseb. e Ruellia cearensis Lindau., endêmica da região nordeste (BFG 2015, 2018). Dessas, Mendoncia blanchetiana é considerada endêmica da Mata Atlântica do Brasil (BFG 2015, 2018).

Para Gesneriaceae, Codonanthe mattos-silvae Chautems, registrada para a Mata Atlântica do Nordeste e distribuída desde a Bahia até Alagoas (Chautems 1991, BFG 2015, 2018) tem aqui sua ocorrência ampliada para Pernambuco. Também foi registrada Drymonia coccinea (Aubl.) Wiehler, amplamente distribuída no Norte e Nordeste do Brasil (BFG 2015, 2018), em áreas florestais de terra baixas a montanas (Melo et al. 2016, Alves et al. 2013), também possui distribuição disjunta amazônica-atlântica, fenômeno recorrente na região da Mata Atlântica ao norte do Rio São Francisco (Andrade-Lima 1982) com vários casos relatados para Pernambuco e para a área de estudo (Pessoa \& Alves 2012, Silva et al. 2012 \& Amorim et al. 2016).

Para Loganiaceae foram registradas Spigelia anthelmia L., espécie ruderal e de ampla distribuição no Brasil (BFG 2015, 2018) e Mitreola petiolata (Walter. ex J.F Gmel.) Torr. \& A. Gray, coletada pela última vez no Estado em 1934 e reencontrada em 2007, tendo aqui um complemento às descrições e ilustrações de Leeuwenberg (1974) e Progel (1868). Para Strychnos, todas as amostras coletadas na área estão em fase estéril, fenômeno comum relatado por Krukoff \& Monachino (1942), que destacam sua fenologia efêmera e ocorrência no dossel das florestas como fatores limitantes à amostragem. A partir de caracteres vegetativos e comparação com materiais adicionais, foi possível identificar Strychnos parvifolia A.DC. e Strychnos cf. atlantica Krukoff \& Barneby.

Chave para identificação das espécies de Acanthaceae, Gesneriaceae Loganiaceae da Usina São José

1. Lianas; venação acródroma (Strychnos)

2. Espinhos ausentes; pecíolo $\geq 0,5 \mathrm{~cm}$ compr., glabro, lâmina foliar $\geq 14 \mathrm{~cm}$ compr., ápice

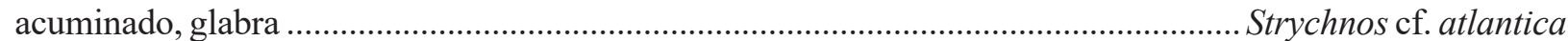

2. Espinhos no caule por vezes presentes; pecíolo $\leq 0,4 \mathrm{~cm}$, pubescente; lâmina foliar $\leq 11 \mathrm{~cm}$ compr., ápice agudo, face adaxial glabra com nervuras pubescentes, face abaxial pubescente ..... Strychnos parvifolia

1. Ervas terrestres ou epífitas, arbustos terrestres, subarbustos hemiepífitos ou epífitos e trepadeiras herbáceas; venação eucamptódroma

3. Estípulas presentes; inflorescências escorpióides ou dicasiais; flores actinomorfas, 5 estames 4. Folhas sésseis, par pseudoverticilado no ápice do caule; inflorescências escorpióides; corola alva com listras róseas ao longo do tubo e lobos; frutos biglobosos, ápice arrendondado ... Spigelia anthelmia

4. Folhas pecioladas, opostas ao longo do caule; inflorescências dicasiais; corola alva; frutos obcordados, ápice bicornudo Mitreola petiolata

3. Estípulas ausentes; inflorescências em racemos curtos, espiciformes, paniculiformes, tirsóides ou flores solitárias; flores zigomorfas, 2-4 estames

5. Ervas ou subarbustos hemiepifíticos ou epifíticos; cálice dialissépalo (Gesneriaceae)

6. Subarbustos hemiepifíticos ou epifíticos; brácteas foliáceas, róseo-avermelhadas ..... Drymonia coccinea 6. Ervas epifíticas, anisófilas (folhas menores estipuliformes); brácteas lineares, verdes Codonanthe mattos-silvae

5. Ervas terrestres eretas ou prostradas, arbustos terrestres ou trepadeiras herbáceas terrestres; cálice gamossépalo (Acanthaceae)

7. Pecíolo alado; folhas deltoides Thunbergia alata

7. Pecíolo cilíndrico; folhas ovadas, elípticas, lanceoladas, oblongas a obovadas

8. Brácteas recobrindo totalmente o cálice

9. Trepadeiras herbáceas; flores não reunidas em inflorescências Mendoncia blanchetiana

9. Ervas eretas; flores reunidas em inflorescências espiciformes Justicia sp.

8. Brácteas recobrindo parcialmente o cálice

10. Lâmina foliar $\geq 13 \mathrm{~cm}$ comp.; corola tubular, não labiada, vermelha 10. Lâmina foliar $\leq 8 \mathrm{~cm}$ comp.; corola bilabiada, alva Ruellia cearensis Lepidagathis alopecuroidea 


\section{Acanthaceae}

Ervas eretas a prostradas, arbustos ou trepadeiras herbáceas, espinhos e gavinhas ausentes. Folhas opostas, isófilas, ao longo do caule; pecíolo alado ou cilíndrico; estípula ausente. Flores solitárias a inflorescências paniculadas, espiciformes ou em tirsos. Brácteas recobrindo ou não o cálice. Flores zigomorfas; cálice gamossépalo; corola gamopétala, ereta em relação ao cálice, lobos glabros, calcar ausente; 2-4 estames, didínamos ou homodínamos, tecas inseridas ou não em alturas diferentes do conectivo, com ou sem apêndices; metaestilete ausente, estilete pubescente ou glabro; estigma glabro; nectários intraflorais presentes em disco ou ausente. Frutos cápsulas ou drupas, glabras.

\section{Justicia sp}

Figura 1a-b

Ervas eretas, ca. $30 \mathrm{~cm}$ alt., ramos esparsamente pubescentes. Pecíolo 0,5-1,0 cm compr., cilíndrico, pubescente; lâmina foliar 5,5-6,5 × 2-2,5 cm, oblonga, membranácea, concolor, estrigosa em ambas as faces, margem inteira, não ciliada, base aguda, ápice atenuado, venação eucamptódroma. Inflorescências espiciformes, axilares e terminais, 13-18 flores. Brácteas 0,6-07 ×0,1-0,2 cm, oblongas a lanceoladas, verdes, hisurtas, recobrindo totalmente o cálice. Tubo do cálice inconspícuo, lobos 0,5-0,6 × 0,02-0,03 cm, filiformes, externamente hirsutos, internamente glabros; corola 1-1,2 × 0,2-0,3 cm, bilabiada, alva na base e diferenciada nas extremidades em lilás, lábio superior unilobado, $0,5-0,6 \times 0,2-0,26 \mathrm{~cm}$, lábio inferior $0,6-0,65 \times 0,66-0,7 \mathrm{~cm}$, tri-lobado, lobo central mais largo; estames $2,0,5-0,6 \mathrm{~cm}$ compr., tecas inseridas em alturas diferentes no conectivo, apêndices ausentes; ovário $0,8 \mathrm{~mm}$ compr., orbicular, estilete 0,7-0,8 cm compr., pubescente na base, estigma $0,1 \mathrm{~mm}$ compr.; disco nectarífero ausente. Frutos não observados.

Material examinado: BRASIL. Pernambuco: Igarassu, Usina São José, Fragmento Piedade, 23-XI-2009, fl., J.A.N. Souza et al. 555 (UFP); ibid., 15-X-2009, fl., J.D. Garcia \& K. Rajput 1174 (UFP).

Pela insuficiência e as condições dos materiais analisados do táxon, não foi possível a sua identificação ao nível específico, necessitando de coletas adicionais na área apesar do amplo esforço já realizado no local desde 2005 conforme Alves-Araújo et al. (2008), Melo et al. (2011) e Alves et al. (2013). Justicia sp. é claramente uma espécie rara no local tendo sido encontrada em sítios ripários, florescendo entre os meses de outubro e novembro. Entre as espécies da área, assemelha-se morfologicamente a Lepidagathis alopecuroidea, porém se diferencia pela base das folhas aguda, dois estames e o lábio superior da corola unilobado.

\section{Lepidagathis alopecuroidea (Vahl) R.Br. ex} Griseb., Fl. Brit. W.I.: 453. 1862.

Figura 1c-e

Ervas eretas a prostradas, ca. $60 \mathrm{~cm}$ alt., ramos glabrescentes. Pecíolo 0,7-1,3 cm compr., cilíndrico, glabro; lâmina foliar 7,5-8 × 2-3 cm, oval a elíptica, membranácea, concolor, estrigosa a glabrescente em ambas as faces, margem inteira, não ciliada, base atenuada, ápice agudo, venação eucamptódroma. Inflorescências em tirsos, axilares, 15-20 flores. Brácteas $0,6-0,8 \times 0,05-0,1 \mathrm{~cm}$, oblongas, verdes, estrigosas, recobrindo parcialmente o cálice. Tubo do cálice inconspícuo, lobos 0,8-0,9 × 0,4-0,5 cm, oblanceolados, externamente pubescentes, internamente glabros; corola 0,5-0,6 × 0,05-0,1 cm, bilabiada, alva, lábio superior $0,2-0,3 \times 0,1-0,2 \mathrm{~cm}$, bilobado, lábio inferior 0,3-0,4 × 0,1-0,15 cm, trilobado, lobo central mais largo; estames 4 , 0,4-0,55 cm compr., tecas inseridas em alturas diferentes no conectivo, apêndices ausentes; ovário 0,1-0,2 mm compr., orbicular, estilete $0,6-0,7 \mathrm{~mm}$ compr., base glabra, estigma $0,1-0,2 \mathrm{~mm}$ compr.; disco nectarífero ausente. Frutos não observados.

Material examinado: BRASIL. Pernambuco: Igarassu, Usina São José, Fragmento Zambana, 22-XII-2007, fl., D. Araújo et al. 569 (UFP).

Ocorre desde o Sul do México até o norte da América do Sul e Antilhas (Kameyama 2006). No Brasil tem registro apenas para a região Norte (Amazonas, Pará), Nordeste (Pernambuco e Alagoas) Centro-Oeste (Goiás, Mato Grosso) nos domínios da Amazônia, Cerrado, Mata Atlântica e Pantanal (BFG 2015, 2018). Na área de estudo, foi encontrada na borda dos fragmentos. Pode ser confundida na USJ com Justicia sp., diferenciada pela base das folhas atenuada, quatro estames e o lábio superior da corola bilobado.

3. Mendoncia blanchetiana Profice., Brittonia 49: 67. 1997.

Figura 1f-g

Trepadeiras herbáceas, 0,6-2 $\mathrm{m}$ alt., ramos densamente pubescentes. Pecíolo 1-2 cm 


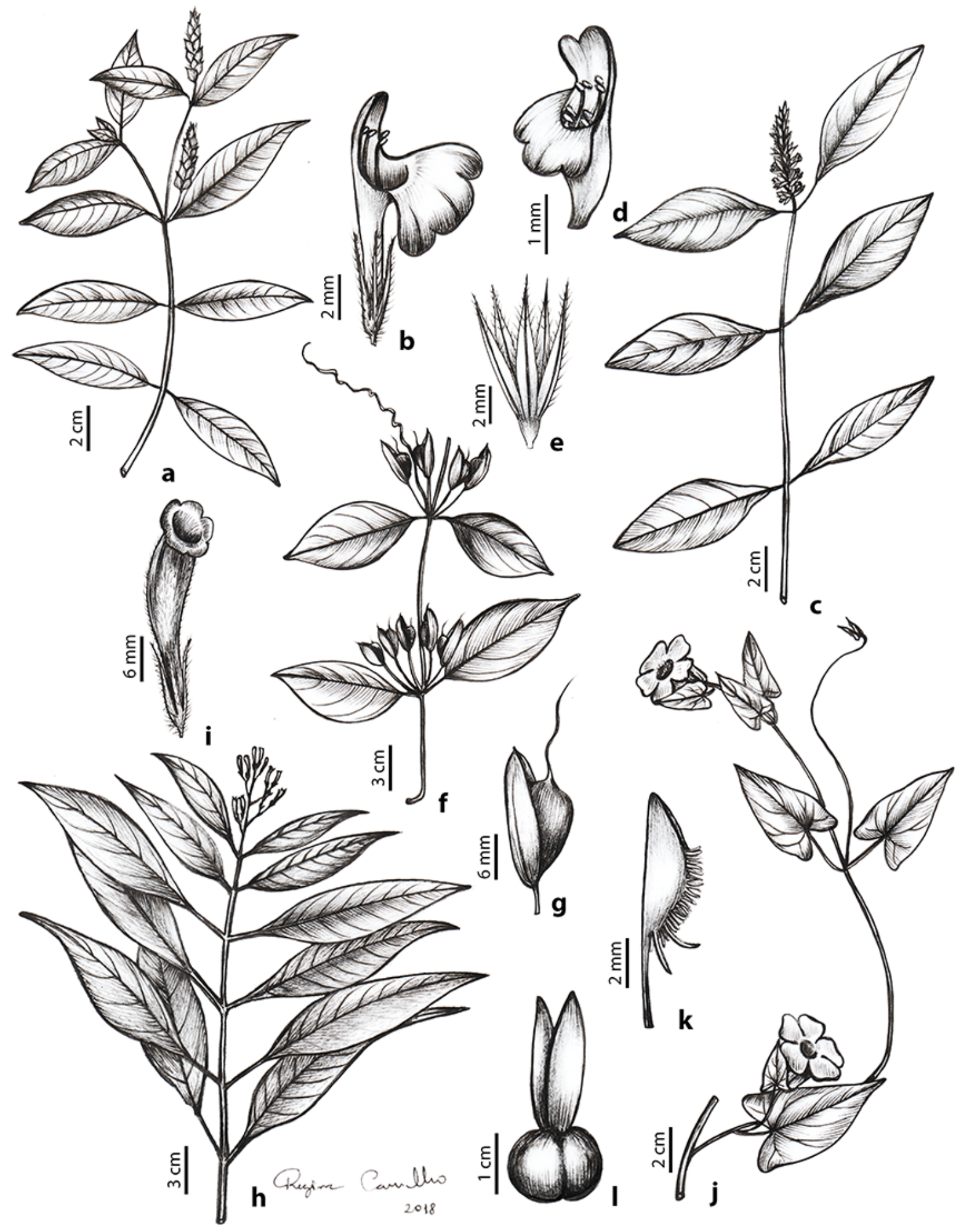

Figura 1. Caracteres diagnósticos da família Acanthaceae. a-b. Justicia sp. a. Ramo florífero. b. Flor. c-e. Lepidagathis alopecuroidea (Vahl) R.Br. ex Griseb. c. Ramo florífero. d. Flor. e. Cálice. f-g. Mendoncia blanchetiana Profice. f. Ramo frutífero. g. Fruto. h-i. Ruellia cearensis Lindau. h. Ramo florífero. i. Flor. j-1. Thunbergia alata Bojer ex Sims. j. Hábito. k. Antera evidenciando os apêndices. 1. Fruto.

Figure 1. Diagnostic characters of the Acanthaceae family. a-b. Justicia sp. a. Floral branch. b. Flower. c-e Lepidagathis alopecuroidea (Vahl) R.Br. ex Griseb. c. Floral branch. d. Flower. e. Calyx. f-g. Mendoncia blanchetiana Profice. f. Fruit branch. g. Fruit. h-i. Ruellia cearensis Lindau. h. Floral branch. i. Flower. j-1. Thunbergia alata Bojer ex Sims. j. Habit. k. Anther showing the appendices. 1. Fruit. 
compr., cilíndrico, pubescente; lâmina foliar 6,5-9,5 × 2,7-5,2 cm, obovada, membranácea, concolor, face adaxial estrigosa, face abaxial pubescente, margem inteira, ciliada, base aguda, ápice acuminado, venação eucamptódroma. Flores axilares, 5-6 por axila. Brácteas 2-2,5 $\times 0,5-0,8 \mathrm{~cm}$, lanceoladas, verdes, pubescentes, recobrindo totalmente o cálice. Tubo do cálice $0,25 \times 0,4 \mathrm{~cm}$ compr., cupular, glabro, lobos ausentes; corola 4,0 $00,8 \mathrm{~cm}$ compr., tubulosa, branca, glabra; estames $4,0,5-0,8 \mathrm{~cm}$ compr., tecas inseridas na mesma altura, apêndices ausentes; ovário $0,3 \mathrm{~cm}$ compr., oblongo, estilete $3,0 \mathrm{~cm}$ compr., glabro; estigma $0,1 \mathrm{~cm}$ compr., disco nectarífero ausente. Frutos drupas, 1,5-2,0 cm compr., oblongas.

Material examinado: BRASIL. Pernambuco: Igarassu, Usina São José, Fragmento Zambana, 22-XII-2007, fr., D. Araújo et al. 570 (UFP); ibid., 19-X-2007, fr., A.A. Araújo et al. 661 (UFP).

Material adicional examinado: BRASIL. Bahia: Santa Luzia, s.d., fl., A.M. Carvalho 4586 (CEPEC).

Mendoncia blanchetiana é endêmica do Brasil, tendo ocorrência registrada até então apenas para Bahia, Pernambuco e Alagoas, no domínio da Mata Atlântica (Profice 1997, Lemos et al. 2010). Na área de estudo, foi encontrada na borda dos fragmentos. Diferencia-se das demais espécies de Acanthaceae da área por possuir 5-6 flores alvas por axila e por ser trepadeira.

4. Ruellia cearensis Lindau., Notizbl. Königl. Bot. Gart. Berlin 6: 195. 1914.

Figura $1 \mathrm{~h}-\mathrm{i}$

Ervas a arbustos, 0,5-2 $\mathrm{m}$ alt. ramos hisurtos. Pecíolo 1-3,2 cm compr., cilíndrico, hirsuto; lâmina foliar 13-21,5 × 3,5-6,1 cm, lanceolada, membranácea, discolor, ambas as faces estrigosas, margem inteira, ciliada, base atenuada, ápice acuminado, venação eucamptódroma. Inflorescências paniculiformes, terminais, 12-15 flores. Brácteas $1-1,3 \times 0,1-0,15 \mathrm{~cm}$, linear-lanceoladas, verdes, hisurtas, recobrindo parcialmente o cálice. Tubo do cálice inconspícuo, lobos 1-1,2 × 0,1-0,12 cm, lanceolados, externamente hirsutos, internamente glabros; corola 2,8-3 × 0,5-0,7 cm, tubulosa, vermelha; estames 4, 1,35-1,5 cm compr., tecas inseridas na mesma altura, apêndices ausentes; ovário 0,2-0,3 cm compr., orbicular, estilete 1,5-1,6 cm compr., glabro, estigma $0,1 \mathrm{~mm}$ compr., disco nectarífero presente. Frutos não observados.
Material examinado: BRASIL. Pernambuco: Igarassu, Usina São José, Fragmento Piedade, 21-XI-2009, fl., J.A.N. Souza et al. 551 (UFP); ibid., Fragmento Zambana, 22-XII-2007, fl., D. Araújo et al. 574 (UFP).

Ruellia cearensis é endêmica do Brasil, e restringe-se a região Nordeste nos Estados de Alagoas, Bahia, Ceará, Paraíba e Pernambuco, onde ocorre nos domínios da Caatinga e Mata Atlântica (BFG 2015, 2018). Na área de estudo, foi encontrada nas bordas dos fragmentos, com destaque para a corola vermelha que é uma exceção, pois a maioria dos espécimes apresentam corola rosa. Se diferencia das demais Acanthaceae da área por possuir flores vermelhas e disco nectarífero presente no ovário.

5. Thunbergia alata Bojer ex Sims., Bot. Mag. 52: 2591. 1825.

Figura $1 \mathrm{j}-1$

Trepadeiras herbáceas, ramos hisurtos. Pecíolo 3,8-4,5 cm compr., alado, hisurto; lâmina foliar 5,5-6,8 × 3,7-4 cm, deltoide, membranácea, concolor, face adaxial hirsuta, face abaxial tomentosa, margem inteira, ciliada, base sagitada, ápice agudo, venação eucamptódroma. Flores solitárias, axilares, 1-2 por axila. Brácteas 1,6-1,0 × 1,0-1,3 cm, deltóides, verdes, estrigosas, recobrindo totalmente o cálice. Tubo do cálice inconspícuo, lobos 0,1-0,2 × 0,01-0,02 cm, lanceolados, hirsutos; corola 0,24-0,32 × 0,8-0,9 cm, hipocrateriforme, tubo preto-purpúrea e lobos laranjas; estames 4, 0,7-0,9 cm compr., tecas inseridas na mesma altura, apêndices presentes; ovário $0,2-0,3 \mathrm{~cm}$ compr., orbicular, estilete 1-1,1 cm compr., glabro, estigma 0,1-0,2 cm compr., disco nectarífero ausente. Frutos cápsulas, 3,3-3,4 cm compr., globosas.

Material examinado: BRASIL. PeRnAmbuco: Igarassu, Usina São José, Fragmento Piedade, 5-IX-2007, fr., D. Araújo et al. 468 (UFP); ibid.,9-XII-2008, fr., E. Pessoa et al. 12 (UFP); ibid., 26-I-2010, fl., D. Cavalcanti et al. 50 (UFP).

Thunbergia alata é nativa das ilhas de Zanzibar e Pomba, na costa leste da Tanzânia (Sims 1825), sendo naturalizada no Brasil, com ocorrência registrada nas regiões Norte (exceto Roraima e Rondônia), Nordeste (Alagoas, Bahia, Pernambuco), Centro-oeste (Goiás), Sudeste (exceto Espírito Santo) e Sul (exceto Rio Grande do Sul), e nos domínios da Amazônia, Caatinga e Mata Atlântica (BFG 2015, 2018). No local de estudo, foi encontrada nas bordas dos fragmentos. 
Se diferencia das demais na área por possuir folhas deltoides, pecíolo alado, flores laranjas com fauce preto-purpúrea e tubo da corola curvado.

\section{Gesneriaceae}

Ervas ou subarbustos, hemiepífitos ou epífitos, espinhos e gavinhas ausentes. Folhas opostas, isófilas ou anisófilas, ao longo do caule; pecíolo cilíndrico; estípula ausente. Flores solitárias ou em racemos curtos. Brácteas recobrindo totalmente ou não o cálice. Flores zigomorfas; cálice dialissépalo, heterosépalo ou homosépalo; corola gamopétala, ereta ou obliqua em relação ao cálice, lobos glabros, calcar presente ou ausente; 4 estames, didínamos, tecas inseridas na mesma altura, sem apêndices; metaestilete ausente, estilete levemente pubescente; estigma glabro; nectários intraflorais laterais ao ovário. Frutos cápsulas, orbiculares, levemente pubescentes.

6. Codonanthe mattos-silvae Chautems, Rev. Brasil. Bot. 14(1): 52. 1991.

Figura 2k

Ervas epífitas, 40-50 cm compr., ramos glabros a glabrescentes. Folhas opostas a pseudo-alternas por anisofilia, folhas menores estipuliformes; pecíolo 0,4-1,3 cm compr., glabrescente a levemente pubescente 2,8-12,8 × 1,0-2,8 cm compr.; lâmina foliar 4,3-21,2 × 1,5-6,7 cm, estreitamente elíptica a elíptica, discolor, glabrescente na adaxial a glabra na abaxial, margem plana a levemente revoluta, glabra, base cuneada, ápice agudo a acuminado, venação eucamptódroma. Flores solitárias, axilares, 1-2 flores; brácteas $0,28-0,3 \times 0,02-0,03 \mathrm{~cm}$, lineares, verdes, levemente pubescentes, não recobrindo o cálice. Cálice heterosépalo, sépala dorsal $0,7-0,8 \times 0,08-0,1 \mathrm{~cm}$, levemente espatulada, levemente pubescentes em ambas as faces, sépalas ventrais $1-1,1 \times 0,06-0,2 \mathrm{~cm}$, lineares, elípticas a espatuladas simétricas a levemente assimétricas; corola 1,56-1,6 × 0,2-0,45 cm, oblíqua em relação ao cálice, hipocrateriforme, branca, externamente levemente pubescente, internamente coberta por indumento glandular, calcar presente, $0,2 \times 0,2 \mathrm{~cm}$; estames 1-1,3 cm compr.; ovário 0,38-0,4 cm compr., estilete 1,2-1,3 cm compr., levemente coberto por indumento glandular, estigma $0,1 \mathrm{~cm}$ compr., glabro. Frutos bagas, $0,6-0,7 \times 0,4-0,45 \mathrm{~cm}$, orbiculares, levemente pubescentes.

Material examinado: BRASIL. Pernambuco: Igarassu, Usina São José, Fragmento Piedade, 5-II-2019, fl., fr., A.R. Macedo et al. 142 (UFP).
Endêmica da Mata Atlântica do Nordeste brasileiro, registrada até então para a Bahia, Sergipe e Alagoas (Chautems 1991, BFG 2015, 2018), sendo este o primeiro registro de ocorrência para Pernambuco. É caracterizada pelo hábito epifítico, folhas anisófilas com a folha menor estipuliforme e cálice heterosépalo, um menor, diferenciado em lacínio dorsal cobrindo o calcar e os dois pares restantes maiores e ventrais em relação a corola. A corola é posicionada obliquamente em relação ao receptáculo floral e com calcar, diferentemente das demais espécies de Codonanthe (Chautems \& Perret 2013).

7. Drymonia coccinea (Aub1.) Wiehler, Phytologia 27: 324. 1973.

Figura $2 \mathrm{i}-\mathrm{j}$

Subarbustos epífitos ou hemiepífitos, ramos glabros. Folhas opostas, isófilas, em todo o caule; pecíolo 2-4 cm compr., glabrescente; lâmina foliar 4,3-21,2 × 1,5-6,7 cm, estreitamente elíptica a oblanceolada, discolor, glabrescente na adaxial, esparçadamente pubescente na abaxial, margem inteira, ciliada, base atenuada, ápice agudo a acuminado, venação eucamptódroma. Inflorescências em racemos curtos, axilares, 2-6 flores; brácteas, 2,3-3,3 $\times 1,6-2,6 \mathrm{~cm}$, largamente ovadas a suborbiculares, róseo-avermelhadas, glabras a glabrescentes, recobrindo totalmente o cálice. Cálice homosépalo, sépalas 1,45-1,5 × 0,7-0,72 cm, obovadas, levemente pubescentes externamente, internamente glabras; corola 4-4,3 × 0,9-1 cm, ereta em relação ao cálice, tubulosa, branco-amarelada, externamente pubescente, internamente glabra, calcar ausente; estames 2-2,15 cm compr.; ovário 0,38-0,4 cm compr., estilete 1,8-1,85 cm compr., papilado, estigma $0,38-0,4 \mathrm{~cm}$ compr., papilado. Frutos não observados.

Material examinado: BRASIL. PeRnAmBUCO: Igarassu, Usina São José, Fragmento Piedade, 29-VII-2007, fl., D. Araújo et al. 387 (UFP); ibid., 10-I-2008, fl., D. Araújo et al. 587 (UFP); ibid., 6-V-2009, fl., T.A. Pontes 187 (UFP); ibid., 24-XI-2009, fl., J.D.G. Gonzalez 1312 (UFP); ibid., 2-III-2010, fl., J.A.N. Souza et al. 629 (UFP).

Material adicional examinado: BRASIL. PERnAMBUCO: Camaragibe, Aldeia, 3-XII-2017, fl., A. Macedo et al. 113 (UFP); Sirinhaém, Usina Trapiche, 20-X-2016, fl., N.K. Luna et al. 362 (UFP). AlAGOAS: Ibateguara, 


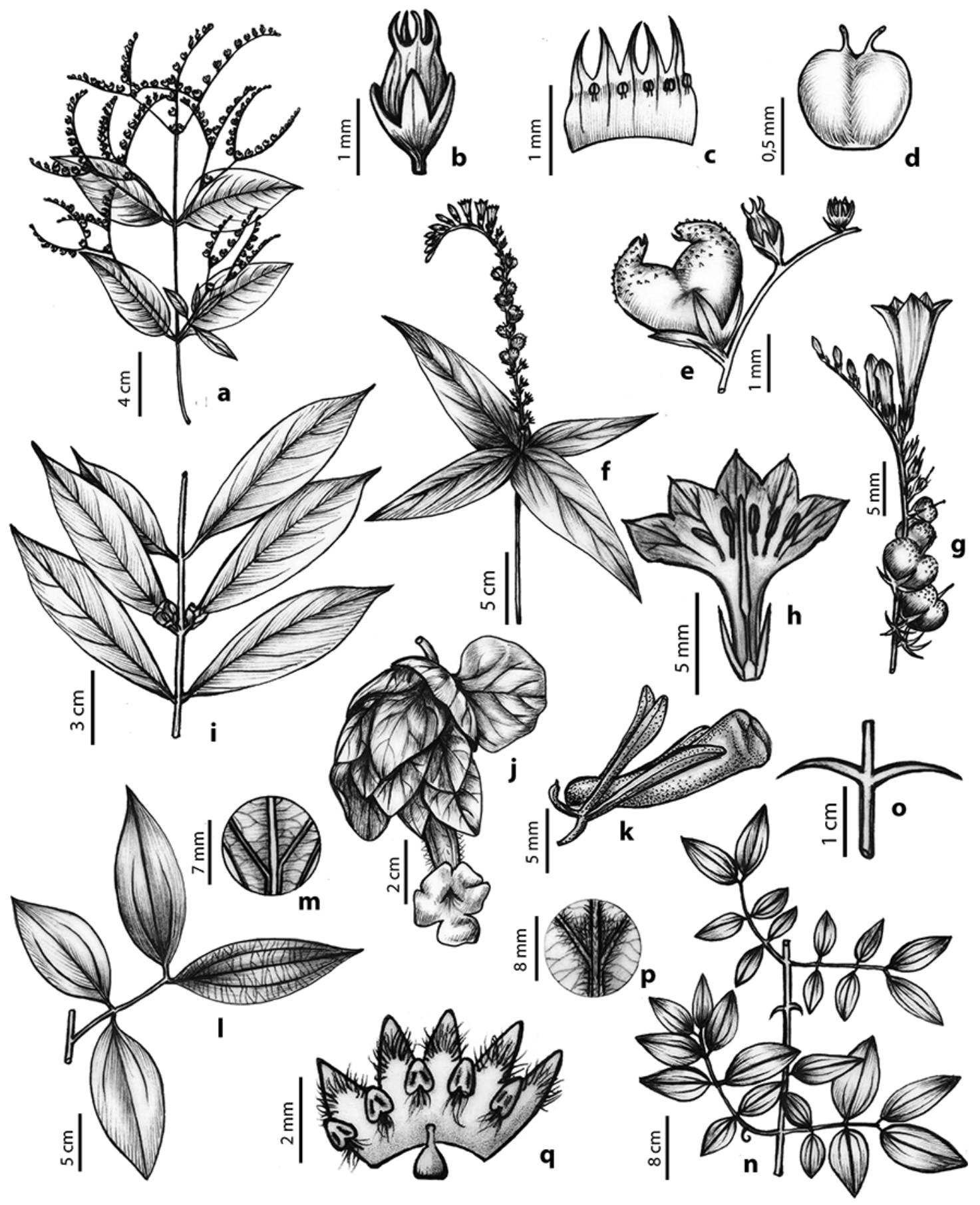

Figura 2. Caracteres diagnósticos das famílias Gesneriaceae e Loganiaceae. a-e. Mitreola petiolata (Walter. ex J.F.Gmel.) Torr. \& A.Gray. a. Ramo florífero e frutífero. b. Flor. c. Corola aberta. d. Gineceu. e. Seção da inflorescência com flores e frutos. f-h. Spigelia anthelmia L. f. Ramo florífero e frutífero. g. Seção da inflorescência com flores e frutos. h. Flor. i-j. Drymonia coccínea (Aubl.) Wiehler. i. Ramo florífero. j. Inflorescência. k. Codonanthe mattos-silvae Chautems. k. Botão floral. 1-m. Strychnos cf. atlantica Krukoff \& Barneby. 1. Ramo. m. Detalhe das nervuras abaxiais. n-q. Strychnos parvifolia A.DC. n. Ramo. o. Espinhos. p. Detalhe das nervuras abaxiais. q. Flor.

Figure 2. Diagnostic characters of the families Gesneriaceae and Loganiaceae. a-e. Mitreola petiolata (Walter. ex J.F.Gmel.) Torr. \& A.Gray. a. Floral and fruit branch. b. Flower. c. Open corolla. d. Gynoecium. e. Section of the inflorescence with flowers and fruits. f-h. Spigelia anthelmia L. f. Floral and fruit branch. g. Section of the inflorescence with flowers and fruits. h. Flower. i-j Drymonia coccinea (Aubl.) Wiehler. i. Floral branch. j. Inflorescence. k. Codonanthe mattos-silvae Chautems. k. Floral bud. 1-m. Strychnos cf. atlatica Krukoff \& Barneby. 1. Branch. m. Detail of the abaxial nerves. n-q. Strychnos parvifolia A.DC. n. Branch. o. Thorns. p. Detail of the abaxial nerves. q. Flower. 
Grota do Varjão, 18-III-2002, fl., M. Oliveira \& A.A. Grilo 882 (UFP).

Registrada para a Bolívia, Colombia, Guiana, Guiana Francesa, Peru e Suriname, (Feuillet \& Steyermark 1999, Feuillet \& Skog 2002) e Brasil, onde é encontrada no domínio amazônico além do Nordeste em Alagoas, Bahia e Pernambuco, na Mata Atlântica (BFG 2015, 2018). Foi registrada na área de estudo em áreas de sítio ripário e tabuleiros. É caracterizada por possuir hábito subarbustivo hemiepifítico ou epifítico, brácteas vistosas róseo-avermelhadas e corola brancoamarelada.

\section{Loganiaceae}

Ervas eretas ou lianas com espinhos e gavinhas, por vezes presentes. Folhas opostas a opostas e pseudoverticiladas, isófilas, concentradas ou distribuídas ao longo do caule; pecíolos cilíndricos ou ausentes; estípulas presentes, por vezes inconspícuas. Inflorescências dicasiais, monocasiais escorpióides ou corimbosas. Brácteas não recobrindo o cálice. Flores actinomorfas; cálice gamossépalo; corola gamopétala, ereta em relação ao cálice, lobos glabros a tomentosos, calcar ausente; 5 estames, homodínamos, tecas inseridas na mesma altura do conectivo, apêndices ausentes; metaestilete presente ou ausente, estilete glabro, estigma cilíndrico ou globoso, papilionado ou glabro; nectários intraflorais ausentes. Frutos cápsulas ou bagas.

8. Mitreola petiolata (Walter. ex J.F.Gmel.) Torr. \& A.Gray, Fl. N. Amer. 2(1): 45. 1841. Figura 2a-e

Ervas eretas, 50-60 cm alt., inermes, ramos glabros. Folhas opostas ao longo do caule; pecíolo 1,4-1,5 cm compr., cilíndrico, glabro; estípulas $0,1-0,12 \mathrm{~cm}$ compr.; lâmina foliar 3,6-7,5 × 1,4-3,8 cm, ovada a oblonga, membranácea, concolor, glabra em ambas as faces, margem inteira, glabra, base arredondada, ápice agudo, venação eucamptódroma. Inflorescências dicasiais, apicais e axilares, 13-16 flores. Brácteas 0,8-1 $\times 0,1-0,2 \mathrm{~mm}$, lineares, verdes, glabras. Tubo do cálice inconspícuo, lobos 0,8-1 × 0,5-0,7 mm, lanceolados, glabros; corola $0,13-0,15 \times 0,08-0,1 \mathrm{~cm}$, urceolada, alva, glabra; estames $0,4-0,5 \times 0,1-0,2 \mathrm{~mm}$; ovário 0,4-0,5 × 0,5-0,6 mm, orbicular levemente achatado, bilobado no ápice, metaestilete ausente, estiletes 2 , livres, 0,1-0,2 mm compr., estigmas 2, livres, ca. 0,1 $\mathrm{mm}$ compr., glabros. Frutos cápsulas, 0,3-0,32 cm compr., obcordadas, ápice cornudo, superfície papilada.
Material examinado: BRASIL. Pernambuco: Igarassu, Usina São José, Fragmento Piedade, 5-IX-2007, fr., A. Alves-Araújo et al. 139 (UFP).

Material adicional examinado: BRASIL. PERNAMBUCO: São Lourenço da Mata, 1-I-1920, fr., B Pickel 665 (IPA); ibid., 30-X-1931, fr., B. Pickel 4644 (IPA); ibid., 13-VIII-1934, fr., B. Pickel 3621 (IPA). BRASIL. Piauí: Floriano, 17-V-1997, fl. e fr., LP. Felix (HST15968); Uruçuí, Barra da Volta, 12-V-2009, fl. e fr., A.M. Miranda et al. 5899 (HST).

Espécie de ampla distribuição nas regiões tropicais e subtropicais do mundo, é conhecida na América do Sul para a Colômbia, Equador, Venezuela (Leeuwenberg 1974) e Brasil, onde possui ocorrência confirmada no Norte apenas no Pará e Tocantins, Sudeste apenas em Minas Gerais e Rio de Janeiro, Nordeste a exceção de Alagoas e Sergipe e CentroOeste com exceção do Mato Grosso do Sul, nos domínios da Amazônia, Caatinga, Cerrado e Mata Atlântica (BFG 2015, 2018). A única coleta no local é oriunda de borda florestal, próxima a canavial, sendo provavelmente invasora de culturas, como observado por Andrade-Lima (1964). É diferenciada de $S$. anthelmia por suas folhas distribuídas por todo o caule, inflorescências dicasiais, corola urceolada e seu fruto obcordado com lobos apicais corniculados.

9. Spigelia anthelmia L., Sp. P1. 1: 149. 1753. Figura 2f-h

Ervas eretas, 25-30 cm alt., inermes, ramos glabros. Folhas opostas na base e pseudoverticiladas no ápice dos ramos; sésseis a subsésseis; estípulas 0,1-0,15 cm compr.; lâmina foliar $5,8-12,5 \times 0,5-6,5 \mathrm{~cm}$, lanceolada, levemente ovada a elíptica, membranácea, concolor, face adaxial escabra, face abaxial glabra, margem inteira, não ciliada, base cuneada a arredondada, levemente irregular, ápice agudo a levemente acuminado, venação eucamptódroma. Inflorescências escorpióides, apicais, 12-32 flores. Brácteas 0,1-0,12 × 0,01-0,02 cm, lineares, verdes, glabras. Tubo do cálice inconspícuos, lobos 0,3-0,32 × 0,04-0,05 cm, lanceolados, glabros; corola 1-1,2 $\times 0,35-0,4 \mathrm{~cm}$, hipocrateriforme, alva com listras róseas, glabra; estames 0,6-0,65 cm compr.; ovário $0,5-0,6 \mathrm{~mm}$ compr., orbicular, metaestilete $0,25-0,27 \times 0,02-0,03 \mathrm{~cm}$, estilete $0,35-0,36 \mathrm{~cm}$ compr., estigma 0,7-0,8 mm compr., papilado. Frutos cápsulas, $0,4-0,45 \mathrm{~cm}$ compr., biglobosas, muricadas.

Material examinado: BRASIL. Pernambuco: Igarassu, Usina São José, Estrada da Usina São José, 
6-IV-1983, fl. e fr., A. Chiappeta \& R. Barreto CEPE 481 (UFP); ibid., Fragmento Chave, 6-IV-2017, fl. e fr., A.R. Macedo et al. 46 (UFP); ibid., Fragmento Piedade, 16-X-2002, fl. e fr., G. Bezerra \& M.J. Silva 44 (PEUFR); ibid., 16-X-2012, fl. e fr., G.J. Bezerra \& R.J. Silva 44 (PEUFR); ibid., 25-I-2017, fl. e fr., A.R. Macedo et al. 18 (UFP); ibid., 6-IV-2017, fl. e fr., A.R. Macedo et al. 53 (UFP); ibid., Fragmento Macacos, 28-III-2003, fl. e fr., A. Melquíades \& G.J. Bezerra 129 (PEUFR).

Ocorre desde a Flórida (EUA) ao sul da América do Sul (Guimarães \& Pereira 1969, Fernandez Casas 2009), além de ser naturalizada em outros países (Leeuwenberg 1961). Spigelia anthelmia está registrada nos domínios da Amazônia, Caatinga, Cerrado, Mata Atlântica e Pantanal e para quase todos os Estados brasileiros, exceto Amapá, Goiás, Minas Gerais e da região Sul (BFG 2015, 2018). É encontrada principalmente nas áreas de bordas florestais, evidenciando sua associação a ambientes antropizados. É diferenciada de $M$. petiolata pelas folhas opostas na base e pseudoverticiladas em dois pares no ápice dos ramos, inflorescências em cimeiras escorpióides, corola hipocrateriforme e frutos biglobosos muricados.

\section{Strychnos}

Lianas, gavinhas e espinhos, por vezes presentes. Estípulas inconspícuas. Folhas ao longo do caule, pecíolo cilíndrico. Inflorescências terminais, corimbosas. Lobos do cálice triangulares; corola tubulosa; ovário orbicular; metaestilete ausente; estigma glabro. Frutos bagas, globosas, lisas.

10. Strychnos cf. atlantica Krukoff \& Barneby, Mem. New York Bot. Gard. 20(1): 61. 1969.

Figura 21-m

Gavinhas lenhosas, ramos glabros, inermes. Pecíolo 0,5-0,8 cm compr., glabro; lâmina foliar 14-19,8 × 4,7-7,5 cm, estritamente ovada a elíptica, coriácea, concolor, glabra, margem inteira, não ciliada, base cuneada a levemente atenuada, ápice acuminado a caudado, venação acródroma imperfeita suprabasal. Flores e frutos não observados.

Material examinado: BRASIL. Pernambuco: Igarassu, Usina São José, Fragmento Piedade, 27-XI-2007, est., J.S. Gomes et al. 316 (UFP); ibid., 18-VIII-2009, est., J.D. Garcia 1132 (UFP); ibid., 1-II2010, est., J.D. Garcia 1412 (UFP); ibid., s.d., est., H.C.H. Silva et al. 147 (PEUFR); ibid., 1-VI-2002, est., H.C.H. Silva \& K.D. Rocha 288 (PEUFR).
Material adicional examinado: BRASIL. PernAmbuco: Rio Formoso, Cupe, Praia do Muro Alto, 6-II-1970, fl., fr., Andrade-Lima 705718 (IPA).

Strychnos atlantica tem distribuição registrada para Bahia, Paraíba, Pernambuco e Espírito Santo (BFG 2015, 2018, Krukoff \& Barneby 1969) incluindo portanto a área de ocorrência das amostras analisadas. $\mathrm{Na}$ região de estudo ocorre em áreas de borda e tabuleiro, onde tem sido coletada unicamente em estado estéril. Aqui, este nome é aplicado devido à semelhança morfológica com as descrições e amostras indicadas por Krukoff \& Barneby (1969) e Brandão \& Rapini (2018), porém na área de estudo não foram visualizados espinhos e as folhas apresentam-se um pouco maiores do que o relatado para Strychnos atlantica, o que pode ser devido a plasticidade fenotípica comum nas espécies do gênero conforme indicado por Krukoff \& Barbeby (1942). Ressalta-se a necessidade de coletas férteis para confirmação da identificação taxonômica, em complemento aos esforços já realizados anteriormente (Alves-Araújo et al. 2008, Melo et al. 2011, Alves et al. 2013). Diferencia-se de Strychnos parvifolia por possuir folhas maiores e geralmente de ápice acuminado além de ramos e folhas glabras. Vale ressaltar que as flores de Strychnos atlantica foram analisadas e descritas após 50 anos da publicação da espécie (Brandão \& Rapini 2017).

11. Strychnos parvifolia A.DC., Prod. 9: 16. 1845. Figura 2n-q

Gavinhas presentes, ramos pubescentes, espinhos em pares; pecíolo 0,3-0,4 × 0,08-0,1 cm, pubescente; lâmina foliar 1,3-11 $\times 1,2-5,1 \mathrm{~cm}$, orbicular a elíptica, membranácea, concolor, face adaxial glabra na superfície e nervuras secundárias, densamente a espaçadamente pubescente na nervuras primária, face abaxial densamente a espaçadamente pubescente na superfície e nervuras secundárias e primárias, margem inteira, curtamente ciliada, base cuneada a levemente arredondada ou cordada, ápice agudo, venação acródroma imperfeita suprabasal. Inflorescências 20-25 flores. Brácteas 0,29-0,3 × 0,07-0,08 cm, lanceoladas, verdes, externamente pubescentes, internamente glabras. Tubo do cálice inconspícuo, lobos 0,18-0,3 × 0,08-0,1 cm, externamente papilosos a levemente pubescentes, internamente glabros, ciliados; corola 0,28-0,3 ×0,18-0,2 cm, alva, lobos internamente tomentosos, externamente glabros; estames $1-1,2$ cm compr.; ovário $0,4-0,5 \mathrm{~mm}$ compr., 
estilete $0,6-0,7 \mathrm{~mm}$ compr., estigma $0,2-0,3 \mathrm{~mm}$ compr. Frutos 2-2,2 cm compr.

Material examinado: BRASIL. Pernambuco: Igarassu, Usina São José, Engenho Campinas, 19-IX-2009, est., L.M. Nascimento \& G. Batista 846 (UFP); ibid., fragmento Piedade, 11-IV-2007, fr., J.S. Marques \& N.A. Albuquerque 16 (IPA); ibid., 4-VII-2007, est., J.S. Gomes et al. 315 (UFP).

Material adicional examinado: BRASIL. PERnAMBUCO: Mirandiba, 11-II-2009, fl., K. Pinheiro 1316 (UFP); Goiana, RPPN Fazenda Tabatinga, 28-II-2011, fr., $D$. Cavalcanti et al. 470 (UFP); ibid., 9-IX-2011, fl., D. Cavalcanti et al. 579 (UFP).

Endêmica da América do Sul, ocorre desde a Mata Atlântica brasileira até as savanas da Bolívia e do Paraguai (Krukoff \& Monachino 1942), sendo amplamente distribuída no Brasil, com registros para quase todos os Estados, à exceção de Alagoas, Roraima, Rondônia, Sergipe e todos os Estados do Sul, habitando os domínios da Amazônia, Caatinga, Cerrado e Mata Atlântica (BFG $2015,2018)$. Na região de estudo é encontrada nas áreas de tabuleiro e borda dos fragmentos, diferenciada de Strychnos cf. atlantica por possuir espinhos lenhosos, que podem estar ou não presentes nas amostras, além de folhas menores, indumento pubescente ao longo das nervuras abaxiais, principalmente próximo as axilas e menos densamente nas nervuras adaxiais, juntamente com sua corola curta e lobos tomentosos.

\section{Agradecimentos}

À Usina São José, ao National Science Foundation (DEB-0946618), ao U.S. National Science Foundation, Velux Stiftung, Beneficia Foundation e principalmente ao $\mathrm{CNPq}$ pela concessão da bolsa de pesquisa. Especiais agradecimentos aos revisores deste manuscrito pelas valiosas contribuições e a equipe do Laboratório de Morfo-Taxonomia Vegetal/UFPE.

\section{Literatura citada}

Alves, M., Alves-Araújo, A., Amorim, B., Araújo, A., Araújo, D., Araujo, M.F., Buril, M.T., Costa-Lima, J., Garcia-Gonzalez, J., Gomes-Costa, G., Melo, A., Novaes, J., Oliveira, S., Pessoa, E., Pontes, T. \& Rodrigues, J. 2013. Inventário de Angiospermas dos fragmentos de Mata Atlântica da Usina São José, Igarassu, Pernambuco. In: M.T. Buril, A. Melo, A. Alves-Araújo \& M. Alves (eds.). Plantas da Mata Atlântica: Guia de árvores e arbustos da Usina São José (Pernambuco). Editora Livro Rápido, Recife, pp. 133-158.
Alves-Araújo, A.G., Araujo, D., Marques, J., Melo, A., Maciel, J.R., Irapuã, J., Pontes, T., Lucena, M.F.A., Bocage, A.L. \& Alves, M. 2008. Diversity of Angiosperms in Fragments of Atlantic Forest in the State of Pernambuco, Northeastern Brazil. Bioremediation, Biodiversity and Bioavailability 2(1): 14-26.

Amorim, B.S., Maciel, J.R., Melo, A. \& Alves, M. 2016. Flora da Usina São José, Igarassu, Pernambuco: Lecytidaceae, Marcgraviaceae e Primulaceae. Rodriguésia 67(4): 971-979.

Andrade-Lima, D. 1964. Plantas Invasoras da Zona da Mata de Pernambuco. Secretaria de Agricultura, Indústria e Comércio/ Instituto de Pesquisas Agronômicas, Recife.

Andrade-Lima, D. 1982. Present-Day Forest Refuges in Northeastern Brazil. In: G.T. Prance (ed.). Biological Diversification in the Tropics. Columbia University Press, New York, pp. 245-251.

APG IV. 2016. The Angiosperm Phylogeny Group An update of the Angiosperm Phylogeny Group classification for the orders and families of flowering plants: APG IV. Botanical Journal of the Linnean Society 181: 1-20.

BFG. 2015. Growing Knowledge: an overview of Seed Plant diversity in Brazil. Rodriguésia 66: 1085-1113.

BFG. 2018. Brazilian Flora 2020: Innovation and collaboration to meet Target 1 of the Global Strategy for Plant Conservation (GSPC). Rodriguésia 69(4): 1513-1527.

Brandão, E.K. \& Rapini, A. 2017. Novelties in Strychnos sect. Breviflorae (Loganiaceae). Phytotaxa 329(3): 262-268.

Brandão, E.K. \& Rapini, A. 2018. Flora da Bahia: Loganiaceae. Sitientibus (Ciências Biológicas) 18: 1-49.

Buril, M.T. \& Alves, M. 2011. Flora da Usina São José, Igarassu, Pernambuco: Convolvulaceae. Rodriguésia 62(1): 93-105.

Chautems, A. 1991. A família Gesneriaceae na região cacaueira da Bahia, Brasil. Revta brasil. Bot. 14: 51-59.

Chautems, A. 2000. Gesneriaceae. In: M.M.R.F. Melo, F. Barros, S.A.C. Chiea, M. Kirizawa, S.L. JungMendaçolli \& M.G.L. Wanderley (eds.). Flora Fanerogâmica da Ilha do Cardoso. Instituto de Botânica, São Paulo, vol. 7, pp. 54-69.

Chautems, A., Baracho, G.S. \& Filho, J.A.S. 2000. A new species of Sinningia (Gesneriaceae) from Northeastern Brazil. Brittonia 52(1): 49-53.

Chautems, A, \& Perret, M. 2013. Redefinition of the Neotropical genera Codonanthe (Mart.) and Codonanthopsis Mansf. (Gesneriaceae). Selbyana 31(2): 143-156.

Chiappeta, A.A. 1985. Estudos taxonômicos da família Loganiaceae em Pernambuco. Dissertação de Mestrado, Universidade Federal Rural de Pernambuco, Recife. 
Christenhusz, M.J.M., Fay, M.F. \& Chase, M.W. 2017. Plants of the World: an illustrated encyclopedia of vascular plants. The University of Chicago Press, USA.

Cortês, A.L.A \& Rapini, A. 2013. Justicieae (Acanthaceae) do semiárido do estado da Bahia, Brasil. Hoehnea 40(2): 253-292.

Costa-Lima, J.L. \& Alves, M. 2015. Flora da Usina São José, Igarassu, Pernambuco: Erythroxylaceae. Rodriguésia 66(1): 285-295.

Denham, M.L. 2004. Gesneriaceae. In: N. Smith, S.A. Mori, A. Henderson, D.W. Stevenson \& S.V. Heald (eds.). Flowering plants of the Neotropics. Princenton University Press, New Jersey, pp. 170-173.

Ducke, A. 1955. O gênero Strychnos no Brasil. Boletim Técnico do Instituto Agronômico do Norte 30: 1-64.

Erbar, C. \& Leins, P. 1996. Distribuition of the character states "Early Sympetaly" and "Late Sympetaly" within the "sympetalae tetracycliae" and presumably allied groups. Plant Biology 109(5): 427-440.

Fernandez-Casas, F.J. 2009. Notas sobre el género Spigelia Linnaeus (Spigeliaceae) en Cuba. Adumbratione ad Summæ Editionem 31: 1-26.

Ferreira, D.M.C, Barbosa, J.I.S \& Alves, M. 2017. Flora da Usina São José, Igarassu, Pernambuco: Polygalaceae. Rodriguésia 68(1): 251-262.

Feuillet, C. \& Skog, L.E. 2002. Gesneriaceae. In: S.A. Mori, G. Cremers, C.A. Garcie, J.J. Granville, S.V. Heald, M. Hoff \& J.D. Mitchell (eds.). Guide to the vascular plants of Central French Guiana. Memoirs of The New York Botanical Garden 76(2): 1-776.

Feuillet, C. \& Steyermark, J.A. 1999. Gesneriaceae. In: J.A. Steyemark, P.E. Berry, K. Yatskievych \& B.K. Holst (eds.). Flora of the Venezuelan Guayana. 5 ed. Missouri Botanical Garden Press, USA, pp. 552-576.

Gibbons, K.L., Henwood, M.J., \& Conn, B.J. 2012. Phylogenetic relationships in Loganieae (Loganiaceae) inferred from nuclear ribosomal and chloroplast DNA sequence data. Australian Systematic Botany 25: 331340.

Gomes-Silva, F., Macedo, A.R., Pessoa, E. \& Alves, M. 2018. Flora da Usina São José, Igarassu, Pernambuco: Chrysobalanaceae, Humiriaceae, Lacistemataceae e Trigoniaceae. Rodriguésia 69(4): 1799-1811.

Guimarães, E.F. \& Pereira, J.F. 1969. Contribuição ao estudo do gênero Spigelia L. III Sinópse das espécies que ocorrem no Brasil. Loefgrenia 34: 1-19.

Harris, J. \& Harris, M. 2001. Plant identification terminology: an illustrated glossary. $2^{\circ}$ ed. Spring Lake Publishing, Payson.

Harvey, Y.B. \& Wasshausen, D.C. 1995. Acanthaceae. In: B.L. Standard. Flora of the Pico das Almas: Chapada Diamantina, Bahia, Brazil. Royal Botanical Garden, KEW, pp. 112-114.

Hickey, L.J. 1973. Classification of architecture of dicotyledonous leaves. American Journal of Botany 60(1): 17-33.
Kameyama, C. 2006. Flora da Reserva Ducke: Acanthaceae. Rodriguésia 57(2): 149-154.

Kameyama, C. 2009. Acanthaceae. In: M. Alves, M.F. Araújo, J.R. Maciel \& S. Martins (eds.). Flora de Mirandiba. Associação de Plantas do Nordeste, Recife, pp 45-48.

Krukoff, B.A. \& Barneby, R.C. 1969. Supplementary notes on the American species of Strychnos. VIII. Memoirs of New York Botanical Garden 20(1): 1-94.

Krukoff, B.A. \& Monachino, J. 1942. The American species of Strychnos. Brittonia 4: 248-322.

Leeuwenberg, A.J.M. 1961. The Loganiaceae of Africa. 3. Spigelia. Acta Botanica Neerlandica 10(4): 460-465.

Leeuwenberg, A.J.M. 1974. The Loganiaceae of Africa. 12. Mitreola L. Mededelingen Landbouwhogeschool Wageninger 74-23: 1-28.

Lemos, R.P.L., Mota, M.C.S., Chagas, E.C.O \& Silva, F.C. (Orgs.). 2010. Checklist-Flora de Alagoas: Angiospermas. Instituto do Meio Ambiente de Alagoas, Alagoas.

Luna, N.K.M., Pessoa, E. \& Alves, M. 2016. Flora da Usina São José, Igarassu, Pernambuco: Zingiberales. Rodriguésia 67(1): 261-273.

Maas, P.J.M \& Westra, L.Y.T. 1993. Neotropical Plant Families: a concise guide to families of vascular plants in the Neotropics. KoeltzScientific Books, Germany/ USA, pp. 195-198.

Maciel, J.R. \& Alves, M. 2014. Flora da Usina São José, Igarassu, Pernambuco: Poaceae. Rodriguésia 65(2): 355-367.

Melo, A., Alves-Araújo, A. \& Alves, M. 2009. Loganiaceae. In: M. Alves, M.F. Araújo, J.R. Maciel, S. Martins (eds.). 2009. Flora de Mirandiba. Associação de Plantas do Nordeste, Recife, pp. 236-239.

Melo, A., Amorim, B., García-González, J., Souza, J., Pessoa, E., Mendonça, E., Chagas, M., Alves-Araujo, A. \& Alves, M. 2011. Updated floristic inventory of the angiosperms of the Usina São José, Igarassu, Pernambuco, Brazil. Revista Nordestina de Biologia 20: 03-26.

Melo, A., Amorim, B.S., Pessoa, A., Maciel, J.R. \& Alves, M. 2016. Serra do Urubu, a biodiversity hotspot for angiosperms in the northern Atlantic Forest (Pernambuco, Brazil). CheckList 12(1): 1842.

Nurit, K., Agra, M.F., Basílio, I.J.L.D. \& Baracho, G.S. 2005. Flora da Paraíba, Brasil: Loganiaceae. Acta Botania Brasilica 19(2): 407-416.

Olmstead, R.G., Kim, K.J., Jansen, R.K. \& Wagstaff, S.J. 2000. The phylogeny of Asteridae sensu lato based on chloroplast $n d f H$ gene sequences. Molecular Phylogenetics and Evolution 16(1): 96-112.

Peixoto, A.L. \& Maia, L.C. 2013. Manual de Procedimentos para herbários. Editora Universitária da UFPE, Recife.

Pessoa, E. \& Alves, M. 2012. Flora da Usina São José, Igarassu, Pernambuco: Orchidaceae. Rodriguésia 62(3): 341-356. 
Profice, S.R. 1997. Two new species of Mendoncia (Acanthaceae) from Bahia, Brazil. Brittonia 49: 67-70.

Progel,A. 1868. Loganiaceae. In: C.F.P. Martius (ed.). Flora Brasiliensis 6(1): 251-300.

Silva, A.G., Sá-e-Silva, I.M.M., Rodal, M.J.N. \& Linse-Silva, A.C. 2008. Influence of edge and topography on canopy and sub-canopy structure of an Atlantic Forest fragment in Igarassu, Pernambuco State, Brazil. Bioremediation, Biodiversity and Bioavailability 2: 41-46.

Silva, F.O., Lourenço, A.R., Pessoa, M.C.R \& Alves, M. 2012. Flora da Usina São José, Igarassu, Pernambuco: Ochnaceae e Quinaceae. Rodriguésia 63(4): 1133-1138.

Silva, M.J., Melo, J.I.M. \& Sales, M.F. 2010. Flora da região do Xingó, Alagoas e Sergipe: Acanthaceae A. Juss. Revista Caatinga 23(2): 59-67.

Sims, M.D.J. 1825. Flower-garden displayed: in which the most ornamental Foreign plants, cultivated in the open ground, the green-house, and the stove, are accurately represented in their natural colours. Botanical Magazine 52: 2591.

Struwe, L. 2004. Loganiaceae. In: N. Smith, S.A. Mori, A. Henderson, D.W. Stevenson \& S.V. Heald (eds.). Flowering plants of the Neotropics. Princenton University Press, New Jersey, pp. 219-221.
Thiers, B. [continuously updated] Index Herbariorum: A global directory of public herbaria and associated staff. New York Botanical Garden's Virtual Herbarium. Disponível em http://sweetgum.nybg.org/science/ih/ (acesso em 6-II-2019).

Trindade, M.B., Lins-e-Silva, A.C.B., Silva, H.P., Figueira, S.B. \& Schessl, M. 2008. Fragmentation of the northern coastal region of Pernambuco, Brazil: Recent changes and implications for conservation. Bioremediation, Biodiversity and Bioavailability 2: 5-13.

Wasshausen, D. 2004. Acanthaceae. In: N. Smith, S.A. Mori, A. Henderson, D.W. Stevenson \& S.V. Heald (eds.). Flowering plants of the Neotropics. Princenton University Press, New Jersey, pp. 3-7.

Woodgyer, E.M. 1995. Gesneriaceae. In: B.L. Standard. Flora of the Pico das Almas: Chapada Diamantina, Bahia, Brazil. Royal Botanical Garden, KEW, pp. 27-28.

Zappi, D.C. \& Setúbal, R.B. 2016. Flora das Cangas da Serra dos Carajás, Pará, Brasil: Loganiaceae. Rodriguésia 67(5): 1405-1409.

Zappi, D.C. 1995. Loganiaceae. In: B.L. Standard. Flora of the Pico das Almas: Chapada Diamantina, Bahia, Brazil. Royal Botanical Garden, KEW, pp. 406-407. 